\title{
The Interaction between Potential Criminals' and Victims' Demands for Guns
}

\author{
Mehmet Bac \\ Sabanci University \\ Faculty of Arts and Social Sciences, \\ Tuzla, Istanbul \\ 34956, Turkey.
}

E-mail: bac@sabanciuniv.edu

phone: (90) 2164839257

fax: (90) 2164839250

\begin{abstract}
I develop a model with endogenous gun ownership and study the interaction between the demands for guns by heterogeneous potential offenders and victims. I show that the interaction depends on pervasiveness of guns, injury probabilities and, in particular, the impact of the gun on the probability of success against armed relative to unarmed adversaries. While the sanction on armed offense is maximal under plausible conditions, the sanction on unarmed offense balances direct deterrence benefits against marginal deterrence costs and corresponding net property losses. Optimal gun control policy disarms all offenders but allows the attractive potential victims to own guns. The paper also discusses the effects of enforcement and price controls on the demands for guns and welfare.
\end{abstract}

JEL Classification Numbers: K14, K42, D78.

Key Words: demand for guns, offender-victim interaction, sanctions, social costs. 


\section{Introduction}

The fact that guns can both cause and deter violent crimes is at the source of the ongoing debate over proper regulation of guns. Proponents of gun control argue that reducing availability of guns will curb violent crimes whereas opponents point out that if only outlaws will have guns when guns are outlawed, law-abiding citizens will be defenseless against encouraged perpetrators. ${ }^{1}$ Understanding the nature of the interaction between potential offenders' and potential victims' demands for guns is important to this causality debate and formulation of sound gun control policies. The present paper makes a theoretical contribution toward this objective and generates new and useful insights for future empirical work.

I study a crime model with endogenous gun ownership by heterogeneous potential offenders and victims, incorporating the detailed parameters of armed and unarmed victim-offender confrontations. Victims' losses and successful offenders' gains are correlated, i.e., when the victim's loss is large, so is the offender's gain. ${ }^{2}$ As a result, only the most effective offenders and the potential victims with large victimization costs acquire a gun. The model also incorporates public deterrence and a social cost objective to evaluate the welfare effects of punishment probability, sanctions and gun control policies.

The analysis shows that the interaction between the two demands for guns depends on the impact of the gun on the success probability of an offense against armed and unarmed victims. Suppose that by switching to acting with a gun the offender produces a larger increase in the probability of successfully completing the offense against unarmed victims. Then, less guns in victims' hands implies more guns in offenders' hands. Conversely, a stimulus on potential victims' demand for guns deters armed offenses: Now the marginal armed offender will drop his gun because the population against which the gun produces a relatively large increase in the probability

\footnotetext{
${ }^{1}$ See for instance Duggan (2001), Cook and Ludwig (2002), Ayres and Donohue (2003) for the pro-control arguments. The opponents, led by Lott (2000), present evidence that more guns in potential victims' hands leads to a fall in violent crimes. Estimates of the number of defensive gun use vary considerably according to U.S. data, but even the relatively conservative figure of 100.000 annual instances offered by Cook and Ludwig (2004) may seem surprisingly large. A much larger estimate is 2.2-2.5 million annual instances, by Kleck and Gertz (1995).

${ }^{2}$ This is a common feature of assault, robbery and burglary, crimes motivated primarily by taking victims' property and valuables; offenders typically value stolen property less than their victims and they often cause damage. One can add sexually motivated crimes to the list.
} 
of success-unarmed potential victims-shrinks. Read from the victims' perspective, the same probability condition implies that an increase in armed offenders prompts an increase in defensive gun ownership. Now that gun ownership produces a larger fall in the probability of harm to property against armed than unarmed offenders, an increase in the measure of armed offenders raises potential victims' expected benefit from gun ownership and induces the marginal unarmed potential victim to buy a gun. ${ }^{3}$

The empirical gun-crime literature does not offer conclusive evidence about the effects of gun ownership on the probability of successful completion of an offense against armed and unarmed victims. These effects would depend on the attributes of the firearm in question as well as several environmental parameters and regulations. Though less plausible, reversal of the probability condition stated above remains a theoretical possibility and should be given a consideration. If acting with a gun the offender typically produces a larger increase in the probability of success against armed than unarmed victims, prevalence of arms enters into the equation. ${ }^{4}$ Now, if the measure of armed potential victims is initially small so that the newly armed victims are wealthy and offensively attractive, an increase in potential victims' demand for guns may well stimulate armed offenses despite the risks involved. Otherwise the sign of the interaction between the two demands remains unchanged.

The sanction on armed offense is maximal under plausible conditions. A crime substitution effect is at work: An increase in the sanction on armed offense will disarm

\footnotetext{
${ }^{3}$ To illustrate, consider a numerical example in which this probability condition holds. Suppose that an unarmed offender's probability of successfully completing the offense is 0.1 against an armed victim and 0.4 against an unarmed victim, whereas if he acts with a gun these probabilities rise to 0.2 and 0.6 , respectively. Therefore by acting with a gun he raises the probability of success by 0.1 if the victim is armed, by 0.2 if the victim is unarmed. Symmetrically, the victim by acquiring a gun can reduce the probability of harm to his property by 0.4 (from 0.6 to 0.2 ) in the case of an armed offense, by 0.3 (from 0.4 to 0.1 ) in the case of an unarmed offense. For this example the model's prediction is that more arms at victims hands reduces armed offenses, whereas more arms at offenders' hands increases gun ownership by potential victims, as mentioned in the paragraph above.

${ }^{4}$ Offenders' first-mover advantage could make this a likely case, as pointed out by a referee. To given an extreme example, suppose that unarmed offenders almost always lose against armed victims and armed offenders almost always win against unarmed victims. If, possibly due to their first-mover advantage, armed offenders are sufficiently likely to win against armed victims and similarly unarmed offenders are sufficiently likely to win against unarmed victims, then the offender by switching to acting with a gun raises the success probability by a small amount if the victim is unarmed, by a large amount if the victim is armed.
} 
potential offenders, which may lead too many potential victims to drop their guns and induce further increases in unarmed offenses. While the latter undesirable effect can be offset partially by raising the sanction on unarmed offense, this chain of reactions may reduce welfare if the net property losses from newly disarmed victims exceed the gains from avoided injuries. However, if injury costs have a sufficiently large weight relative to victims' net property losses, then the sanction on armed offense is maximal. As for the sanction on unarmed offense, it is determined predominantly by the balance between direct deterrence benefits for the unarmed offense and marginal deterrence costs for the armed offense.

The analysis also offers a number of insights on gun control policies. A general increase in the cost of the gun quite effectively reduces the demands for guns. Effectively, because it selectively disarms potential offenders and potential victims: victims who continue to afford guns are also those who risk large property losses if left unprotected, and the armed offenders who drop their guns are those who produce the largest net property losses in their group. Similar considerations are at work in determining the optimal quantity and allocation of guns in the society. Because sanctions are bounded from above and disarming potential victims dilutes deterrence of the unarmed offense, the optimal policy offers potential victims who risk large property losses an option to own guns and disarms the rest of the population.

While the empirical literature on the causality between availability of guns and crime is large and growing, formal studies of the interaction between criminals' and potential victims' demands for guns are scarce. Among the notable contributions, Chaudhri and Geanakoplos (1998) show the negative effect of a tax on guns whereas Donohue and Levitt (1998) endogenize the decision to fight in armed offender-victim encounters and show that an asymmetric arm power is likely to generate less violent outcomes than a symmetric one. Ghatak (2001) models the interaction as a contest game but assumes homogeneous criminals and victims; his model does not capture intra- and inter-group external effects of gun ownership. Mialon and Wiseman (2005) come closest to the present analysis in that they also endogenize gun ownership (and include also the choice of "lying low" for potential victims.) They assume homogeneous offender and victim populations and focus on the mixed-strategy equilibrium of their model to generate predictions about the impact of gun control and sanctions. The modeling approach in this paper is quite different. Most importantly, the populations are heterogeneous and victim-offender encounters can generate net 
property losses as well as separately accounted injury costs. The present analysis thus explains equilibrium interaction and gun ownership by offenders and victims as a function of distribution characteristics and a rich set of relevant parameters in victim-offender confrontations.

In Section 2 I develop the model and in Section 3 I expose the expected payoffs and social costs from offender-victim confrontations. Section 4 studies the interaction between the two groups' decisions and Section 5 investigates the equilibria and optimal sanctions. Optimal gun control policy is derived next, in Section 6, which also presents results on the welfare and incentive effects of the likelihood of punishment and price controls. Section 7 offers concluding remarks.

\section{The Model}

A society comprises two groups of individuals, potential offenders and potential victims. The groups are of equal size, normalized to one. Potential victims differ in their privately known losses, denoted $h$, from a successful offense. Let $G:[0, \infty) \rightarrow[0,1]$ denote the cumulative distribution function of $h$, with continuous density function $g($.$) . The loss h$ excludes the individual cost from potential injury during the offense. This is denoted separately by $c$ and is assumed common to offenders and victims.

Potential offenders differ in their private benefit from the offense. This heterogeneity is represented by the parameter $\alpha \in[0,1]$, with cumulative distribution function $F($.$) and continuous density function f($.$) . An offender's realized private$ benefit is correlated with his victim's loss: more precisely, successfully completing the offense against a type- $h$ victim yields the benefit $\alpha h$ to the type- $\alpha$ offender.

Potential offenders and potential victims decide on whether to acquire a gun, at cost $x$, and potential offenders who choose to act (armed or unarmed) are each randomly matched with one victim. ${ }^{5}$ A match is denoted XY where $\mathrm{X}$ stands for the offender's choice (A if armed, U if unarmed) and Y stands for the victim's choice. Let $q$ denote the probability of own injury when the adversary is armed. An offender-

\footnotetext{
${ }^{5}$ In the model there is one type of arm which has no other use for offenders than to facilitate crime, no other use for the victims than to resist crime. The cost $x$, assumed identical for simplicity, could differ among offenders and potential victims to account for the fact that offenders acquire their guns through the underground secondary market or theft rather than legal market transactions (Cook et al (2007)); then, $x$ would represent the cost of theft or the price in the underground market for offenders, the market price for potential victims.
} 
Table 1: Probabilities of successful offense and punishment according to match type

\begin{tabular}{|c|c|c|c|c|}
\hline \hline Probability of: & AA-match & AU-match & UU-match & UA-match \\
\hline Successful offense & $1-q$ & 1 & $\phi_{U}$ & $\phi_{A}(1-q)$ \\
Punishment & $q+(1-q) \mu$ & $\mu$ & $\mu$ & $q+(1-q) \mu$ \\
\hline \hline
\end{tabular}

victim match has a rich set of potential outcomes, displayed in Table 1 according to match type.

Throughout the paper a successful offense means that the offender reaps the private benefit $\alpha h$ and the victim loses $h$. When the offense fails, the victim, himself injured or not, avoids losing $h$. The assumptions below on the links between injury outcomes, success of the offense and detection outcomes are motivated by analytical simplicity.

Offenders are more likely to be apprehended and punished if injured than not. To economize on notation I assume that the injured offender fails and is punished with probability one. If not injured, he is punished with probability $\mu<1$. $^{6}$ To capture the fact that an armed offense is more likely to be successfully completed if the victim is unarmed, I set the probability of a successful armed offense to one if the victim does not own a gun. On the other hand, an armed offender succeeds only if he avoids injury, thus with a smaller probability $1-q$, against a victim who carries a gun. As for the offender who acts without a gun, he succeeds with probability $\phi_{U}$ if the victim is unarmed, with probability $\phi_{A}(1-q)$ if the victim too is armed, where $1>\phi_{U}>\phi_{A}(1-q)$.

These assumptions imply that the offender's probability of success is largest when he has a gun while the victim does not (in the AU-match), followed by the UU-match, and lowest in the UA-match. ${ }^{7}$ Basically, the gun improves its owner's chances, to succeed for the offender, to avoid the loss $h$ for the victim.

\footnotetext{
${ }^{6}$ Injured offenders are more likely to be caught than uninjured offenders. The assumption that the injured offender is punished with probability one economizes on notation. The same motivation applies for the assumption of a common punishment probability for armed and unarmed offenses. The qualitative effect of a larger punishment probability for the armed offense is transparent.

${ }^{7}$ Kleck (1991) reports that attempted rape and robberies are less often successful against armed victims than victims who do not use a weapon; see also Kleck and Gertz (1995) and the references cited therein, and generally, Cook (1991).
} 
Sanctions are monetary. ${ }^{8}$ The sanction for unarmed offense $s_{U}$, and the sanction for armed offense $s_{A}$ (with or without injury to the victim) are determined by the state within the interval $[0, \bar{s}] .{ }^{9}$ Potential offenders who choose to comply are not sanctioned and get zero; similarly a potential victim who is not matched with an offender gets zero.

Two remarks are in order before proceeding with the payoffs from matching outcomes. First, offenders decide on whether to acquire a gun and act under incomplete information about the status of their prospective victim; symmetrically, potential victims do not know whether they will be visited by an offender, armed or unarmed. Second, an offender's expected benefits from matching with an armed and unarmed victim are different not only because the probabilities of success and injury differ, but also because gun ownership depends on victims' types $h$, which is correlated with the private benefit from a successful offense, $\alpha h$.

\section{The Matches, Payoffs and Choices}

The AA-match presents the largest set of potential outcomes. With probability $q^{2}$ the adversaries injure each other, the offender fails, is detected and punished. He gets $-c-s_{A}$ while the victim gets $-c$. With probability $q(1-q)$ only the offender is injured and gets the payoff $-c-s_{A}$, whereas the victim receives zero. In the symmetric case only the victim is injured. This time the offender succeeds, but is detected and punished with probability $\mu$; the offender's payoff is $\alpha h-\mu s_{A}$ and the victim's payoff is $-h-c$. Finally, in the no injury outcome the offender's payoff is again $\alpha h-\mu s_{A}$ while the victim gets $-h$. Therefore expected payoffs in AA-matches are

$$
U_{O}^{A A}=(1-q) \alpha h-q c-[q+\mu(1-q)] s_{A} \quad \text { and } \quad U_{V}^{A A}=-q c-(1-q) h .
$$

In UU-matches the probability of injury is zero. The offense succeeds with prob-

\footnotetext{
${ }^{8}$ The impacts of nonmonetary and costly sanctions are well known; see, e.g., Polinsky and Shavell (1999) and Polinsky (2000). These issues are tangential to the objectives of this paper.

${ }^{9}$ Allowing for differential sanctions according to the victim's injury status does not add an interest to the analysis because injury is modeled as a random event. Including the level of care as a choice to reduce the adversary's probability of injury would justify differential sanctions, but this would complicate the analysis considerably. See Donohue and Levitt (1998) for a model in which the choice to use the gun (modeled as a choice between fighting and not fighting) is endogenous.
} 
ability $\phi_{U}<1$ and the offender is detected with probability $\mu$. The payoffs are

$$
U_{O}^{U U}=\phi_{U} \alpha h-\mu s_{U} \quad \text { and } \quad U_{V}^{U U}=-\phi_{U} h .
$$

When the offender has a gun but the victim does not (the $A U$-match), the payoffs are

$$
U_{O}^{A U}=\alpha h-\mu s_{A} \quad \text { and } \quad U_{V}^{A U}=-h-q c .
$$

Finally, in a $U A$-match, the offender is caught and imposed the sanction $s_{U}$ with probability $\mu(1-q)+q$. He succeeds and reaps the benefit $\alpha h$ with probability $\phi_{A}(1-q)$. Now the payoffs are

$$
U_{O}^{U A}=\phi_{A}(1-q) \alpha h-[\mu(1-q)+q] s_{U}-q c \quad \text { and } \quad U_{V}^{U A}=-\phi_{A}(1-q) h .
$$

Denote by $\beta$ the probability of an offense per potential victim and by $\tau$ the probability that the offender is armed. Both probabilities are endogenously determined in the analysis. The expected payoff of a potential victim can be written as

$$
\begin{array}{ll}
E U_{V}^{A}=-\tau \beta[q c+(1-q) h]-(1-\tau) \beta \phi_{A}(1-q) h-x & \text { if victim is armed, } \\
E U_{V}^{U}=-\tau \beta[q c+h]-(1-\tau) \beta \phi_{U} h & \text { if victim is unarmed. }
\end{array}
$$

Comparing $E U_{V}^{A}$ and $E U_{V}^{U}$ reveals that a potential victim will acquire a gun if

$$
h>\frac{x}{\beta\left(\tau q+(1-\tau)\left(\phi_{U}-\phi_{A}(1-q)\right)\right)} \equiv \zeta .
$$

Low- $h$ individuals stay unarmed, high- $h$ individuals acquire a gun. The critical victimization cost $\zeta$ defines the potential victim type indifferent between the two options and determines the measure of unarmed potential victims, $G(\zeta)$. Given the assumption $\phi_{U}>\phi_{A}(1-q)$, note that $G(\zeta)<1$ and the measure of armed potential victims is positive as long as $\beta$, the probability of an offense per potential victim, is positive.

Potential offenders' choices will depend on the proportion of armed and unarmed victims. Armed victims have large $h$ values but also carry large risks of injury and punishment, whereas unarmed victims are safe targets but have low $h$ values. The expected payoff from an unarmed offense can be written as

$$
E U_{O}^{U}(\alpha)=\phi_{U} \int_{0}^{\zeta} \alpha h g(h) d h+(1-q) \phi_{A} \int_{\zeta}^{\infty} \alpha h g(h) d h-M s_{U}-(1-G(\zeta)) q c
$$


where $M=G(\zeta) \mu+(1-G(\zeta))[q+\mu(1-q)]$ is the effective probability of punishment. Similarly, the expected payoff from an armed offense is

$$
E U_{O}^{A}(\alpha)=\int_{0}^{\zeta} \alpha h g(h) d h+(1-q) \int_{\zeta}^{\infty} \alpha h g(h) d h-M s_{A}-(1-G(\zeta)) q c-x
$$

Comparing the payoffs in (2) and (3) yields useful preliminary results. First, the larger the offender's $\alpha$, the larger the difference between $E U_{O}^{A}(\alpha)$ and $E U_{O}^{U}(\alpha)$ provided $E U_{O}^{A}(\alpha)>E U_{O}^{U}(\alpha)$, hence, the stronger is the offender's incentive to act armed. So, for two potential offenders $\alpha_{1}$ and $\alpha_{2}$ such that $\alpha_{1}>\alpha_{2}$, if type- $\alpha_{2}$ acts armed, so does type- $\alpha_{1}$; if type- $\alpha_{1}$ complies, so does type- $\alpha_{2}$. Second, if $s_{A} \leq s_{U}$, $E U_{O}^{A}(\alpha)>E U_{O}^{U}(\alpha)$ for all $\alpha$ as long as the cost of the arm, $x$, is not too large. Therefore $s_{A}>s_{U}$ is required to induce some offenders to drop their arms and act unarmed. Third, the set of potential offenders who choose to comply is always nonempty given positive injury costs and sanctions; this set occupies the lower end of the interval $[0,1]$. Unarmed offenders form an "intermediate" group with $\alpha$ values between those who will comply and those who act armed. ${ }^{10}$

\section{The Interaction between the Demands for Arms}

Understanding the interaction between gun ownership decisions by potential victims and offenders is crucial for the formulation of sound gun control policies. This section clarifies the conditions under which the two demands for guns feed each other, beginning with the impact of an increase in defensive gun ownership on armed and unarmed offenses. More precisely, I study the impact of a change in $\zeta$ on two critical $\alpha$ levels, defined below, which determine the partition of potential offenders according to their choices:

The offender of type $\alpha_{U}(\zeta)$ is indifferent between complying and acting unarmed. For this offender, $E U_{O}^{U}\left(\alpha_{U}(\zeta)\right)=0$, that is,

$$
\alpha_{U}(\zeta)=\frac{(1-G(\zeta)) q c+M s_{U}}{\phi_{U} \int_{0}^{\zeta} h g(h) d h+\phi_{A}(1-q) \int_{\zeta}^{\infty} h g(h) d h} .
$$

The offender of type $\alpha_{\tau}(\zeta)$ is indifferent between acting armed and unarmed, provided $\alpha_{\tau}(\zeta)<1$. Otherwise set $\alpha_{\tau}(\zeta)=1$ :

$$
\alpha_{\tau}(\zeta)=\min \left\{1, \frac{x+M\left(s_{A}-s_{U}\right)}{\left(1-\phi_{U}\right) \int_{0}^{\zeta} h g(h) d h+\left(1-\phi_{A}\right)(1-q) \int_{\zeta}^{\infty} h g(h) d h}\right\} .
$$

\footnotetext{
${ }^{10}$ Note that it cannot be optimal for a potential offender to obtain an arm and then act unarmed.
} 
The measure of armed offenders is $1-F\left(\alpha_{\tau}(\zeta)\right)$, the measure of unarmed offenders is $F\left(\alpha_{\tau}(\zeta)\right)-F\left(\alpha_{U}(\zeta)\right)$ and the measure of complying individuals is $F\left(\alpha_{U}(\zeta)\right)$. Proposition 1 follows from differentiation of (4) and (5).

Proposition 1 An increase in the measure of armed potential victims leads to a fall in the number of offenses: $\partial \alpha_{U}(\zeta) / \partial \zeta<0$. It also leads to a fall in the measure of armed offenders, $\partial \alpha_{\tau}(\zeta) / \partial \zeta<0$, if

$$
\alpha_{\tau}(\zeta) \zeta\left[q+\phi_{A}(1-q)-\phi_{U}\right]+q(1-\mu)\left(s_{A}-s_{U}\right)>0
$$

Increased defensive gun ownership deters offenders by raising the likelihood of punishment and by reducing the expected benefit from the offense (the denominator in (4)) because offenders are less likely to succeed against armed victims, of which more are present.

Consider the qualitative impact on the measure of armed offenders. Stated in (6), the sign of $\partial \alpha_{\tau}(\zeta) / \partial \zeta$ shows the reaction of the offender who is indifferent between acting armed and unarmed. Of the two terms in this expression, the second is related to expected costs: The larger is $s_{A}$ relative to $s_{U}$, the stronger the deterrence effect of increased defensive gun ownership. As for the first term in (6), it represents the effect through the change in the expected gross benefits from an armed offense relative to an unarmed offense. Here, as well as in the determination of the optimal sanctions in the next section, the sign of $q+\phi_{A}(1-q)-\phi_{U}$ is a crucial issue. It is useful to write this term as $\left[1-\phi_{U}\right]-\left[1-q-\phi_{A}(1-q)\right]$ : Switching to acting armed, an offender increases the probability of success by $(1-q)-\phi_{A}(1-q)$ when the victim is armed, by $1-\phi_{U}$ when the victim is unarmed (see Table 1.) Therefore an increase in gun ownership by potential victims reduces the relative expected benefit from switching to acting armed if $(1-q)-\phi_{A}(1-q)<1-\phi_{U}$, or if $q+\phi_{A}(1-q)>\phi_{U}$, that is, if the gun produces a larger absolute increase in the probability of successful offense when the victim is unarmed than armed.

The changes in the offense success probabilities underlying this condition would depend on the technical properties of the gun as well as environmental factors and public enforcement policies. The empirical literature does not offer a conclusive evidence for or against $q+\phi_{A}(1-q)>\phi_{U}$. If it holds and the sanction on armed offense is not too low relative to the sanction on unarmed offense, the model delivers an unambiguous prediction: more guns at victims' side implies less guns at offenders' side. It is worth noting that the intensity (if not the sign) of this deterrence effect depends on the pervasiveness of arms, visible in (6) by the term $\alpha_{\tau}(\zeta) \zeta$. If $q+$ 
$\phi_{A}(1-q)>\phi_{U}$, less guns in at least one side (larger $\alpha_{\tau}(\zeta)$ and/or $\zeta$ ) will amplify the deterrence effect in question.

Of course, the opposite case, i.e., $q+\phi_{A}(1-q)<\phi_{U}$, should not be ruled out. It may be that by acting with a gun the offender generates a larger absolute increase in the probability of success against an armed victim than against an unarmed victim. In this case the sign of the inequality in (6) may be reversed, leading the marginal unarmed offenders located at the left neighborhood of $\alpha_{\tau}(\zeta)$ to act armed in response to an increase in gun ownership by potential victims. This outcome is more likely to arise if initially few potential victims own guns ( $\zeta$ is large) because the newly armed potential victims will be the attractive large- $h$ types, promising large expected benefits to the offenders. Stated differently, an increase in gun ownership by potential victims cannot further escalate armed offenses in a context of widespread gun ownership. If it does, gun ownership must be rare-an environment perhaps more closely approximated by the U.K., Austria or Luxembourg than the U.S. ${ }^{11}$ Any policy that encourages defensive arms should therefore carefully evaluate the parameters and initial conditions of victim-offender interactions summarized in (6).

Consider now potential victims' response to a change in the partition of potential offenders according to gun ownership. I define a critical potential victim type, $\zeta_{B}$, who is indifferent between staying unarmed and acquiring a gun:

$$
\zeta_{B}\left(\alpha_{U}, \alpha_{\tau}\right)=\frac{x}{\left(1-F\left(\alpha_{\tau}\right)\right) q+\left[F\left(\alpha_{\tau}\right)-F\left(\alpha_{U}\right)\right]\left(\phi_{U}-\phi_{A}(1-q)\right)} .
$$

A larger $\zeta_{B}$ means a fall in gun ownership by potential victims.

Proposition 2 An increase in unarmed offenses leads to an increase in potential victims' demand for guns: $\partial \zeta_{B}\left(\alpha_{U}, \alpha_{\tau}\right) / \partial \alpha_{U}>0$. If some unarmed offenders are induced to act with a gun, the measure of armed potential victims will increase (escalation effect), that is, $\partial \zeta_{B}\left(\alpha_{U}, \alpha_{\tau}\right) / \partial \alpha_{\tau}>0$, if and only if $q+\phi_{A}(1-q)>\phi_{U}$.

Because the net expected benefit $E U_{V}^{A}-E U_{V}^{U}$ from defensive gun ownership is increasing in the probability of an offense, the impact of $\alpha_{U}$ on $\zeta_{B}$ should not be surprising. As for the impact of a larger measure of armed offenders, it also depends

\footnotetext{
${ }^{11}$ Ownership of firearms is much more prevalent in the U.S. than many other industrialized countries, according to an international survey reported in Killias (1993). The U.S. leads the list with its 48 percent armed households and England and Wales is at the bottom with less than one percent armed households. See also Kates and Mauser (2007).
} 
on whether $q+\phi_{A}(1-q)$ is larger or smaller than $\phi_{U}$. When $q+\phi_{A}(1-q)>\phi_{U}$ holds, switching to defensive gun ownership generates a larger reduction in the probability of harm to property against armed offenders (from 1 to $1-q$ ) than against unarmed offenders (from $\phi_{U}$ to $\phi_{A}(1-q)$ ). Then the potential victim of type $\zeta_{B}$ will not be indifferent to an increase in the measure of armed offenders. He will respond by acquiring a gun, so, gun ownership by potential victims will rise.

\section{Sanctions}

An equilibrium is a partition $\left\{\alpha_{U}^{*}, \alpha_{\tau}^{*}, \zeta^{*}\right\}$ induced by individuals' choices, satisfying (4), (5) and (7):

$$
\alpha_{U}^{*}=\alpha_{U}\left(\zeta^{*}\right), \quad \alpha_{\tau}^{*}=\alpha_{\tau}\left(\zeta^{*}\right) \quad \text { and } \quad \zeta^{*}=\zeta_{B}\left(\alpha_{U}^{*}, \alpha_{\tau}^{*}\right)
$$

It is easy to verify that in any equilibrium, the measure of potential offenders who comply, $F\left(\alpha_{U}^{*}\right)$, the probability of an offense per potential victim, $1-F\left(\alpha_{U}^{*}\right)$, and the measure of armed and unarmed potential victims are positive ( $\zeta^{*}$ is finite). The probability of an offense is positive because with finite sanctions the most effective (large- $\alpha$ ) potential offenders will prefer to act, whereas a positive measure of ineffective (low- $\alpha$ ) potential offenders comply given the possibility of injury and detection. On the other hand, potential victims with sufficiently large victimization costs will find it optimal to arm themselves whenever the probability of an offense is positive, but those whose victimization cost is small will remain unarmed.

The analysis below studies the impact of sanctions on social costs and equilibrium measures of armed and unarmed potential offenders and victims. The main conclusion is that at least one of the two sanctions is maximal and under plausible conditions this is the sanction on armed offense. I begin with the formulation of the social cost objective which the state minimizes by choosing the sanctions $s_{U}$ and $s_{A}$ on unarmed and armed offenses.

$$
\begin{gathered}
S C=\int_{\alpha_{\tau}^{*}}^{1}\{\int_{0}^{\zeta^{*}} \underbrace{[(1-\alpha) h+q c] g(h) d h}_{\mathrm{AU} \operatorname{costs}}+\int_{\zeta^{*}}^{\infty} \underbrace{[(1-q)(1-\alpha) h+2 q c] g(h) d h}_{\mathrm{AA} \operatorname{costs}}\} f(\alpha) d \alpha \\
+\int_{\alpha_{U}^{*}}^{\alpha_{\tau}^{*}}\{\int_{0}^{\zeta^{*}} \underbrace{\phi_{U}(1-\alpha) h g(h) d h}_{\mathrm{UU} \operatorname{costs}}+\int_{\zeta^{*}}^{\infty} \underbrace{\left[\phi_{A}(1-q)(1-\alpha) h+q c\right] g(h) d h}_{\mathrm{UA} \text { costs }}\} f(\alpha) d \alpha
\end{gathered}
$$


Sanctions play a dual role in this objective: they deter crime and influence the demands for arms, hence, the expected net property loss and violence per offense. For a small increase in any one of the two sanctions, let $\Delta \alpha_{U}^{*}, \Delta \alpha_{\tau}^{*}$, and $\Delta \zeta^{*}$ denote the induced change in, respectively, the critical potential offender who is indifferent between committing an unarmed offense and complying, the critical potential offender indifferent between acting armed and unarmed, and the critical victimization cost generating indifference between acquiring a gun and staying unarmed. Because a change in sanctions modifies the equilibrium measures of unarmed and armed offenders as well as the measure of armed potential victims, it is useful to decompose the change in social costs in (8) accordingly, into three parts. The first line gives the effect of a rise in a sanction on social costs through the change it induces in $\alpha_{\tau}^{*}$, the second and third lines through the change in $\zeta^{*}$, and the fourth line through the change in $\alpha_{U}^{*}$ :

$$
\begin{aligned}
\Delta S C= & -\left\{q c+\left(1-\alpha_{\tau}^{*}\right)\left[\int_{0}^{\zeta}\left(1-\phi_{U}\right) h g(h) d h+\int_{\zeta}^{\infty}(1-q)\left(1-\phi_{A}\right) h g(h) d h\right]\right\} \Delta \alpha_{\tau}^{*} \\
& +\left\{\int_{\alpha_{\tau}^{*}}^{1} q\left((1-\alpha) \zeta^{*}-c\right) g\left(\zeta^{*}\right) f(\alpha) d \alpha\right. \\
& \left.+\int_{\alpha_{U}^{*}}^{\alpha_{\tau}^{*}}\left[\left(\phi_{U}-\phi_{A}(1-q)\right)(1-\alpha) \zeta^{*}-c q\right] g\left(\zeta^{*}\right) f(\alpha) d \alpha\right\} \Delta \zeta^{*} \\
& -\left(1-\alpha_{U}^{*}\right)\left\{\int_{0}^{\zeta^{*}} \phi_{U} h g(h) d h+\int_{\zeta^{*}}^{\infty}\left[\phi_{A}(1-q) h+c q\right] g(h) d h\right\} \Delta \alpha_{U}^{*}
\end{aligned}
$$

Investigating the cost effects of isolated increases in each sanction will produce insights about the effects of combined increases in the sanctions. Consider first a small increase in the sanction on armed offense, $s_{A}$. The first-order impact of this modification is to reduce the measure of armed offenders, i.e., $\Delta \alpha_{\tau}^{*}>0$. Assuming $\phi_{U}<q+\phi_{A}(1-q)$, i.e., the gun produces a larger absolute increase in the probability of successful offense when the victim is unarmed than armed, by Proposition 2 potential victims' demand for arms will fall: $\Delta \zeta^{*}>0$. The fall in armed potential victims, in turn, will encourage unarmed offenses by Proposition 1, leading to $\Delta \alpha_{U}^{*}<0$, which means that compliance falls. These modifications generate the following effects on social costs: The fall in armed offenders reduces the social costs represented by the negative first line expression in (8). But the fall in compliance increases social costs; this indirect effect on potential offenders' choices between complying and acting unarmed leads some marginally complying individuals to acting unarmed, as stated in 
the fourth line in (8). Finally, stated in the second and third lines is the impact on social costs through the increase in the critical victimization cost $\zeta^{*}$, beyond which potential victims choose to acquire a gun. The fall in the measure of armed potential victims has a negative effect on social costs if the resulting fall in expected injury costs dominates the rise in expected net property losses, formally, if $c$ is sufficiently large and/or if the status quo measure of armed potential victims is large $\left(\zeta^{*}\right.$ small, so that $(1-\alpha) \zeta^{*}$ is small).

On the other hand, a small increase in the sanction on unarmed offense generates the opposite first-order effects: $\Delta \alpha_{U}^{*}>0$ and $\Delta \alpha_{\tau}^{*}<0$ (see (4) and (5).) The first is a cost-reducing effect that comes from the fall in unarmed offenses (direct deterrence effect), leading to an increase in the measure of complying potential offenders. The second is a cost-increasing effect due to the increase in armed offenders who switch from acting unarmed (marginal deterrence effect.) Overall, then, the measure of unarmed offenders falls because some will switch to compliance whereas others will switch to acting with a gun. These will affect potential victims' expected payoffs, hence, the measure of armed potential victims. However, under the assumption $\phi_{U}<q+\phi_{A}(1-q)$, the final impact on gun ownership by potential victims is ambiguous because while the rise in compliance reduces their demand for guns, the rise in the measure of armed potential offenders increases potential victims' payoffs from acquiring a gun.

A full mathematical characterization of the optimal sanctions is out of reach given the broad cost objective incorporating both armed and unarmed offense costs and the complexity of the interaction between offenders and victims. However, the fact that the two sanctions have opposite effects on offenders' incentives suggests that a joint increase in the sanctions can eliminate the undesirable cost effects that arise from isolated increases in each sanction. Indeed, inspecting (5) reveals that there is an appropriate combined increase in the two sanctions that keeps the measure of armed offenders constant while raising compliance, hence, reducing unarmed offenses. By (7) this will lead to a fall in gun ownership by potential victims. The effects on social costs can be seen in (8), where $\Delta \alpha_{\tau}^{*}=0, \Delta \alpha_{U}^{*}>0$, and $\Delta \zeta^{*}>0$. The fall in unarmed offenses means an increase in the measure of complying individuals and unambiguously reduces social costs, whereas the effect of fewer guns in potential victims' hands depends on injury costs relative to net property losses. Therefore a joint increase in the two sanctions reduces social costs if the resulting cost savings from fewer injuries more than offset the expected increase in net property losses. 
Proposition 3 The optimal sanction on armed offense is maximal if the expected injury costs from an offense are large relative to net property losses.

While the sanction on armed offense is maximal unless perhaps in the case of very small injury costs, the sanction on unarmed offense will be determined predominantly by the balance between direct deterrence benefits for the unarmed offense and marginal deterrence costs for the armed offense.

\section{Policies}

\subsection{Enforcement}

With costless sanctions and costly law enforcement, at least one of the sanctions is maximal and the optimal probability of punishment balances the marginal costs and the social benefits from crime deterrence and reductions in harm and injuries. This well-known general prescription also holds in the present setup. Below I highlight the specific effects of increasing the probability of punishment on crime and gun ownership.

Recall that punishment follows with probability one if the offender is injured, with probability $\mu$ if the offender avoids injury. In this model, an increase in the probability of punishment deters offenders as a group, armed plus unarmed. This follows from differentiation of (4). To isolate the effect on armed offenses, note that the offender's probabilities of punishment and injury depend on the victim's gun ownership, not on the offender's choice between acting with and without a gun. Then the qualitative effect of an increase in the probability of punishment on the measure of armed offenders depends solely on relative sanctions. In the standard case where the sanction on armed offense is maximal and exceeds the sanction on unarmed offense, an increase in $\mu$ will definitely reduce the measure of armed offenders. ${ }^{12}$

Reductions in the probability of an offense and gun ownership at offenders' side will affect potential victims' demand for guns. The rise in compliance will induce

\footnotetext{
${ }^{12}$ It is worth noting that if the possibility of avoiding injury depends on the offender's gun ownership as well, then punishment probabilities would differ accordingly and the relative sanction condition above would be qualified by the respective injury probabilities for armed and unarmed offenses. On the other hand, if the probability of punishment for armed and unarmed offenses were independent and controlled separately (respectively, $\mu_{A}$ and $\mu_{U}$,) it would be possible to raise $\mu_{A}$ alone and generate an unconditional fall in the measure of armed offenders, i.e., no matter the sizes of the two sanctions.
} 
the marginally armed potential victims to drop their guns, and the fall in armed offenses will reinforce this effect under the plausible condition $\phi_{U}<q+\phi_{A}(1-q)$. The optimal probability of punishment balances the potential benefits from fewer injuries and harm to property against direct law enforcement costs.

\subsection{Price Controls}

The cost of a gun can be affected by license fees, taxes, or more subtle policies such as outlawing cheap variants. The impact of these policies on the two crimes and gun ownership is as follows.

Proposition 4 A general increase in the cost of guns reduces gun ownership by both potential victims and offenders, but increases the measure of unarmed offenders, hence, the probability of an offense per potential victim.

A higher cost of the gun generates first-order increases in $\alpha_{\tau}^{*}$ and $\zeta^{*}$, that is, reduces gun ownership by potential offenders and victims. By Proposition 1, this reduces compliance. Because the deterrent price effect on the demands for guns is not surprising, I focus below on the impact on unarmed offenses. According to Proposition 4, the rise in unarmed offenders will exceed the fall in armed offenders, implying growth of the population of offenders (armed plus unarmed), hence, an increase in the probability of an offense per potential victim. The intuition for this result is rooted in the crime substitution effect. Holding potential victims' demand for guns constant, an increase in the cost of guns induces some armed offenders to act unarmed. If this were the total effect, the population of offenders would remain constant. Therefore what raises the probability of an offense per potential victim is the price effect on potential victims' demand for guns. The fall in this defensive demand invites new unarmed offenders, producing more offenses but less violence.

Thus, the optimal price control, if feasible, is to raise the cost of guns to the point of effectively disarming the population of offenders and potential victims. Setting aside the possibility of promoting the trade in guns in secondary black markets, raising the cost of guns to extremely high levels is not optimal for two reasons: First, as shown in the next subsection, individuals whose potential victimization costs are very large should continue to afford guns for their protection. Second, excessively disarming potential victims encourages less effective potential offenders switch from compliance to acting unarmed, which can generate large property losses. It is worth 
noting that the price control discussed above does not discriminate between defensive and offensive demands for guns. If it is the defensive demand that is primarily affected by price controls, then a more conservative price control policy is called for.

\subsection{Quantity Controls}

The target of quantity controls is to impose firearm scarcity, typically by instituting a screening process and standards to prevent unqualified applicants' ownership of guns. In this model the unqualified group is determined endogenously and consists of all potential offenders plus a set of individuals with low victimization costs (low- $h$ potential victims.) The optimal policy is the solution to the problem of choosing the combination of sanctions, $s_{A}^{X}$ and $s_{U}^{X}$, as well as the critical types of offenders and victims $\alpha_{\tau}^{X}$ and $\zeta^{X}$, that minimize expected social costs. ${ }^{13}$ It combines these instruments to reduce the harmful effects of gun ownership and crime to the extent possible while properly taking into consideration the impact of defensive gun ownership on protection and deterrence.

Proposition 5 Under the optimal policy, $\alpha_{\tau}^{X}=1,0<\zeta^{X}<\infty$ and $s_{A}^{X}=s_{U}^{X}=\bar{s}$ : sanctions are maximal, all potential offenders and a positive measure $G\left(\zeta^{X}\right)$ of low- $h$ potential victims are unarmed, where the critical victimization cost $\zeta^{X}$ is given by (A1) in the Appendix. The measure of unarmed offenders $1-F\left(\alpha_{U}^{X}\right)$ is positive, where $\alpha_{U}^{X}=\alpha_{U}\left(\zeta^{X}\right)$ is determined by (4).

Disarming potential offenders eliminates armed offenses and unambiguously reduces social costs. Given this, a reduction in the measure of unarmed offenders can only reduce social costs, which explains the maximal sentence on unarmed offense, $s_{U}^{X}=\bar{s}$. The interesting feature of the optimal gun control policy is that it allows for gun ownership by a positive measure of high- $h$ potential victims, for two reasons: First, there is a social benefit from providing better property protection by arming high$h$ individuals. Second, arming these potential victims increases unarmed offenders' risk and reduces the probability of an offense per potential victim. The optimal gun control policy balances these benefits against expected injury costs.

\footnotetext{
${ }^{13}$ The optimal policy described in Proposition 5 is a second-best. It does not achieve the first-best no-guns-no-crime outcome because full deterrence of unarmed offenses cannot be implemented via finite sanctions given the presence of criminally extremely "lucrative" target victims.
} 
If feasible and administration costs reasonably small, quantity controls can generate important welfare gains relative to price controls and unregulated equilibria. Under optimal quantity control, AA and AU costs will be zero while UU and UA costs may be larger or smaller than unregulated equilibria. But the overall balance will point to lower social costs because any equilibrium outcome without quantity control can be implemented with quantity controls simply by assigning the guns demanded at the former equilibrium.

It is useful to contrast these results with Mialon and Wiseman (2005), who study a crime model in which agents are homogeneous and choose between acquiring a gun and not, in addition to complying for the potential criminals and "lying low" (complete property protection at a cost) for potential victims. Full gun control in their model is an outcome in which the cost of the gun is prohibitively large so that no agent acquires a gun, all potential victims "lie low" and fully protect themselves but suffer a loss of freedom, whereas potential offenders randomize between complying (now a weakly dominated option) and acting unarmed. Accordingly, they argue that it may be optimal to allow some gun ownership by potential victims in order to eliminate the threat of an unarmed attack and the consequent loss of welfare from lying low for potential victims. ${ }^{14}$ Proposition 5 demonstrates that this intuition is correct. In the present model full gun control does not eliminate all crime because sanctions are bounded and potential victims cannot buy full protection against unarmed offenses-there will always be unarmed offenders chasing the high- $h$ attractive potential victims.

I close this section with the model's implications about the limitations on defensive use of guns. Typically, these limitations take the form of sanctions on causing injury or death of an unarmed offender. Introducing such a sanction reduces potential victims' expected payoff from gun ownership, which means an increase in $\zeta^{*}$, a fall in defensive gun ownership. By Proposition 1, the probability of an offense (armed or unarmed) per potential victim will rise. The measure of armed offenders will also rise if the assumption $\phi_{U}<q+\phi_{A}(1-q)$ is maintained. That is, if by acting with a gun the offender produces a larger absolute increase in the probability of success against unarmed than armed victims, a policy that reduces gun ownership by potential victims (such as a limitation on defensive gun use) will prompt more of armed offenses.

\footnotetext{
${ }^{14}$ In passing, their full gun-control equilibrium on which this recommendation is based collapses if one introduces an infinitesimally small cost $\epsilon$ for an unarmed offense.
} 


\section{Concluding Remarks}

This paper develops a model of crime with heterogeneous potential victims and offenders, endogenous gun ownership and a rich class of outcomes from victim-offender encounters. Offenders' and potential victims' demands for guns are related to each other through the correlation between victims' types and the private benefits from an offense as well as the technology of violence involving parameters such as individual injury probabilities and the likelihood of a successful offense conditional on gun ownership. The paper characterizes the interdependence between the two demands and evaluates the welfare effects of sanctions and gun control policies.

The social cost objective in the analysis is relatively broad and includes detailed cost expressions corresponding to property losses and potential injuries in unarmed and armed encounters. It excludes, however, the costs from potential suicidal or accidental uses of guns. While the empirical guns-crime debate is centered around lethal costs (in part for data availability and statistical reasons), this paper stresses the side effects of policies that aim at reducing lethal costs. These side effects include the responses of armed and unarmed offenses to a fall in defensive gun ownership and the crime substitution effects of policies that affect the expected payoffs from armed and unarmed offenses. ${ }^{15}$ An interesting extension of the model would be to add police as a player to study how the interaction between endogenous private and public enforcement modifies the policy prescriptions and the relations between defensive and offensive demands for guns.

The paper identifies a probability condition for the sign of the cross-demand effects. Based on a comparison between the changes in the probability of a successful offense against an armed relative to an unarmed victim when an offender switches to acting with a gun, the condition determines whether more of potential victims will disarm when more of the offenders act armed, and vice versa. It also plays an important role in determining the welfare effects of gun control policies. Its assessment should be of primary importance for empirical research in this field.

\section{Appendix}

\footnotetext{
${ }^{15}$ Lott and Mustard (1997) offer evidence for the substitution effect, arguing that robbers resort to property crimes of stealth to avoid the newly armed population of potential victims following adoption of right-to-carry laws. A recent estimate of the marginal social cost of gun prevalence by Cook and Ludwig (2006) is in the order of $\$ 100$.
} 


\section{Proof of Proposition 5}

The result on the optimal $\alpha_{\tau}$ follows from the partial derivative of $S C$. We have $\partial S C / \partial \alpha_{\tau}<0$ because

$$
-\left(1-\alpha_{\tau}\right) \int_{0}^{\zeta}\left(1-\phi_{U}\right) h g(h) d h-\left(1-\alpha_{\tau}\right) \int_{\zeta}^{\infty}\left(1-\phi_{A}\right)(1-q) h g(h) d h-q c<0 .
$$

Therefore, $\alpha_{\tau}^{X}=1$. Using this fact in the expression of $S C$, we have

$$
\frac{\partial S C}{\partial \zeta}=g(\zeta)\left\{\int_{\alpha_{U}}^{1} \zeta\left(\phi_{U}-\phi_{A}(1-q)\right)(1-\alpha) f(\alpha) d \alpha-\left(1-F\left(\alpha_{U}\right)\right) q c\right\} .
$$

The optimal $\zeta$ is positive and given by

$$
\zeta^{X}=\frac{\left(1-F\left(\alpha_{U}^{X}\right)\right) q c}{\left(\phi_{U}-\phi_{A}(1-q)\right) \int_{\alpha_{U}^{X}}^{1}(1-\alpha) f(\alpha) d \alpha}>0,
$$

where $\alpha_{U}^{X}$ is determined by (4) given $\zeta^{X}$.

Acknowledgements. I am grateful to two anonymous referees for very useful comments. All remaining errors are mine.

\section{References}

Ayres, I., Donohue, J.J., 2003. Shooting Down the "More Guns, Less Crime" Hypothesis. Stanford Law Review 55, 1193-1245.

Chaudhri, V., Geanakoplos, J., 1998. A Note on the Economic Rationalization of Gun Control. Economics Letters 58, 51-53.

Cook, P.J., 1991. The Technology of Personal Violence, in: Tonry, M. (Ed.), Crime and Justice: A Review of Research. University of Chicago Press, pp. 1-70.

Cook P.J., Ludwig, J., 2004. Principles for Effective Gun Policy. Fordham Law Review 73, 589-613.

Cook P.J., Ludwig, J., 2006. The Social Costs of Gun Ownership. Journal of Public Economics 90, 379-391.

Cook P.J., Ludwig, J., Venkatesh S., Braga, A.A., 2007. Underground Gun Markets. Economic Journal 117, 588-618. 
Donohue, J.J., 2004. Guns, Crime, and the Impact of State Right-to-Carry Laws. Fordham Law Review 73, 623-652.

Donohue, J.J., Levitt, S.D., 1998. Guns, Violence, and the Efficiency of Illegal Markets. American Economic Review? 463-467.

Duggan, M., 2001. More Guns, More Crime. Journal of Political Economy 109, 1086-1114.

Ghatak, M., 2001. Gun Control and the Self-Defense Argument. mimeo, University of Chicago.

Hemenway, D., 2004. Private Guns, Public Health. The University of Michigan Press, Ann Arbor.

Kates, D.B., Mauser, G., 2007. Would Banning Firearms Reduce Murder and Suicide? Harvard Journal of Law and Public Policy. 30, 649-694.

Killias, M., 1993. "Gun Ownership, Suicide, and Homicide: An International Perspective," in: Alvazzi, A. et el. (Eds.), Understanding Crime: Experiences of Crime and Crime Control. United Nations Interregional Crime and Justice Research Institute, Rome. pp. 289-306

Kleck, G., 1991. Point Blank: Guns and Violence in America. Aldine, New York.

Kleck, G., 1997. Targeting Guns: Firearms and their Control. Aldine, New York.

Kleck, G., Gertz, M., 1995. Armed Resistance to Crime: the Prevalence and Nature of Self-Defense with a Gun. Journal of Criminal Law and Criminology. 86, 150-187.

Lott, J.R., 2000. More Guns, Less Crime. The University of Chicago Press, Chicago.

Lott J.R., Mustard, D., 1997. Crime, Deterrence and Right-to-Carry Concealed Handguns. Journal of Legal Studies. 26, 1-68.

Mialon, H.M., Wiseman, T., 2005. The Impact of Gun Laws: A Model of Crime and Self-defense. Economics Letters. 88, 170-175.

Polinsky, A.M., 2006. The optimal use of fines and imprisonment when wealth is unobservable. Journal of Public Economics. 90, 823-835. 
Polinsky, A.M., Shavell, S., 1999. On the Disutility and Discounting of Imprisonment and the Theory of Deterrence. Journal of Legal Studies. 28, 1-16. 